\title{
Teachers and teacher aides initiating five-year-olds into science
}

Anne Thwaite

Correspondence:

a.thwaite@ecu.edu.au

School of Education, Edith Cowan

University, Bradford St, Mt Lawley 6050, Australia

\section{Springer}

\begin{abstract}
Apprenticing children into discourses necessary for success at school begins at a very early age. In this paper I look at five-years-olds being introduced to Science and Technology while at the same time being involved in talk around literacy. The various adults who surround the children engage differentially in talk and action while merging the discourses of literacy and science.

Data for this study were obtained during the course of the project 'Early literacy through science in Indigenous and culturally diverse communities', funded by Edith Cowan University in Australia from 2009-2010, in which the author was involved as a researcher. The project involved observing and recording a series of lessons over nine weeks in a Pre-Primary classroom of five year-olds from diverse backgrounds in a metropolitan school. Various functional analyses were used in order to bring out some of the differences in the discourse of the trained teachers compared with that of the other adults working with the children. Analyses included Field, Tenor, Exchange Structure and Speech Function. Differences were apparent in the structure of the discourse, Questions, Commands, vocabulary and the teacher-student relationships. As an example of the contrast between teachers and teacher aides, I look more closely at two lessons involving photography and use of electronic resources. These lessons show the teachers and the teacher aide constructing different relationships with the children and the teacher using a wider variety of linguistic resources in her interactions.
\end{abstract}

Keywords: Classroom discourse analysis; Science discourse

\section{Introduction}

On beginning their schooling, young children must be apprenticed into the discourses that are necessary for this educational context and that may differ greatly from those they are accustomed to using in their homes and communities. This paper presents some analysis of a unit of work (nine weeks of lessons) during which two classes of five-year-olds were introduced to Science and Technology and associated literacies. The discourse of these learning experiences blends scientific concepts with the literacies needed by young children. This discourse is engaged in differentially by the various adults who surround the children: this paper will explore some of the differences in how the various adults initiate the children into ways of talking and doing in this context. In a previous, jointly-authored paper on the same dataset (Thwaite \& McKay 2013), I described how teachers shape the discourse. In the present paper the

(c) 2014 Thwaite; licensee Springer. This is an open access article distributed under the terms of the Creative Commons Attribution License (http://creativecommons.org/licenses/by/2.0), which permits unrestricted use, distribution, and reproduction in any medium, provided the original work is properly cited. 
focus is particularly on the differences between the trained teachers and the other adults who worked with the children.

\section{Background}

The Organisation for Economic Co-Operation and Development's Programme for International Student Assessment (PISA) define Scientific literacy as:

"the capacity to use scientific knowledge, to identify questions and to draw evidencebased conclusions in order to understand and help make decisions about the natural world and the changes made to it through human activity." (New South Wales Department of Education and Training 1999-2011)

It is essential to integrate Science with other curriculum areas so that children can develop their Scientific literacy over a broad range of contexts (Rennie 2005). In an early childhood classroom, teachers need to involve children actively, giving them opportunities to manipulate their environment, solve problems and make decisions, especially through hands-on activities (Seefeldt \& Galper 2007). While real experiences are an important base for learning, it is vital that teachers scaffold the activities so that children are given opportunities to engage in meaningful talk, both with each other and with the teacher (DuVall 2001). This paper will investigate how teachers and other adults working with the children carry out this role, in one particular context.

I will first describe the methods used in the study; following this, various analyses will be outlined and illustrated. These include Register, Discourse structure and dynamics, Exchange Structure, Speech Function and Mood. The paper will conclude with a discussion of the differences found in the discourse of teachers compared with that of teacher aides.

\section{Methods}

Data for this study were obtained during the course of the project: "Early literacy through science in Indigenous and culturally diverse communities", funded by Edith Cowan University from 2009-2010. The author was involved in this project as a researcher. All names of teachers and children given here are pseudonyms.

The aim of the study was to describe how teachers conducted a unit of work in Science and Technology with a group of 50 young children. A series of lessons was observed over nine weeks in a metropolitan Pre-Primary classroom (five year-olds). The children came from various backgrounds, including Indigenous Australian, African, Chinese and South American. As well as Australian English, children spoke languages including Amharic, Japanese, Mandarin, Spanish, Swedish and Vietnamese.

Researchers audio-recorded and took photographs of two focus groups of children over the nine weeks. The children's journals were also copied. The present author was involved in observing and recording one of the focus groups of children. There were three teachers and several other adults, including teacher aides, parents and the school chaplain, working with the children. The teachers have three or four years' training. The teacher aides, including the Aboriginal/Islander Education Officers (AIEOs), have one year training. The other adults, including the school chaplain, have no relevant training. Some teacher aides are encouraged to upgrade their qualifications to a 
university degree and become teachers. However, this can be a long process if they are undergoing study as well as working. In a classroom of five-year-olds, there will always be at least one teacher aide working alongside the teacher. In classrooms with older children, the presence of one or more aides may depend on the children's abilities, cultural and linguistic needs. Aides may not be present full-time.

In this paper I will describe and compare some of the interactions, using a set of functional linguistic analyses described below. The focus of the description will be on some of the differences between interactions involving teachers and those involving other adults, especially teacher aides.

\section{Analyses}

Various functional analyses have been used to investigate the data, including:

- Register: the analysis focuses primarily on the Field, what is happening and the nature of the social action; it also deals with the Tenor, the relationships among the participants (Halliday \& Hasan 1985, p. 12).

- Discourse structure and dynamics: turn length, turn-taking

- Exchange Structure: predictable and unpredictable moves in the discourse (Berry 1981a,b,c; Ventola 1987).

- Speech Function: exchanges of Information or Goods and Services, and Mood: realizations of Speech Function in the grammar (Halliday \& Mathiessen 2004, pp. 108-110).

These analyses are briefly outlined below.

\section{Register}

Here we use Martin's interpretation of Halliday's register theory, in which Field, Tenor and Mode are seen as "register variables", resources for investigating ideational, interpersonal and textual meanings in many kinds of texts (Martin \& Rose 2007, p. 243). As mentioned above, the Register analysis focuses mainly on the Field and the Tenor; these were the variables found to be most productive in describing the differences between teachers and teacher aides. The Field analysis looks at the sequence of activities undertaken by the children and adults during the nine-week unit of work. Vocabulary, in terms of content words (nouns, verbs, adjectives and adverbs) is examined in terms of how it represents an initiation into scientific discourse. The Tenor analysis investigates the relationships constructed between the adults and the children, for example in respect of knowledge of the children's home lives and identity.

\section{Discourse structure and dynamics}

This is a simple analysis of turn number and length, in relation to who holds the floor and the opportunities children are given to contribute to the discourse.

\section{Exchange structure}

An Exchange Structure analysis (Berry 1981a,b,c; Ventola 1987; Martin \& Rose 2007) enables us to see how the discourse unfolds, with regard to both predictable (synoptic) 
and unpredictable (dynamic) moves. Synoptic moves fit into the basic exchange formula of (X2) X1 (X2F), where X can be either A (an action exchange) or K (a knowledge exchange) and $\mathrm{F}$ represents a 'follow-up' move. The numeral 1 represents a primary knower or actor's move, and the numeral 2 represents a secondary knower or actor's move. For example, a K2 move could be a Question and the following K1 move the answer to that Question. An A1 move could be an Offer and an A2F move an acknowledgement of that Offer.

The formula can be extended to account for further synoptic moves:

((DX1) X2) X1 (X2F (X1F))

Here D refers to the 'delaying' moves that are very common in classroom discourse; for example:

Teacher (dk1): What is Australia's national animal?

Student (k2): The kangaroo.

Teacher (k1): That's right. Well done.

The X1F move is a follow-up to an acknowledging move; for example:

John (a1): Have a banana.

Mei (a2f): Thanks. Very kind of you.

John (a1f): Don't mention it.

The dynamic moves in the exchange interrupt the predictable formula and include such things as backchannels, confirmations and clarifications. See Thwaite (1993) for a very brief introduction to the Exchange Structure analysis and some examples. Jones, Kervin \& McIntosh (2011) illustrate how Exchange Structure can be applied to classroom interaction, in their recent article discussing the effects of interactive whiteboards (IWBs) on the discourse. They found that while the IWB entered the classroom as a bearer of content, it had a considerable effect on the interactivity of the discourse (p. 57).

\section{Speech function and mood}

Initiating utterances are classified according to whether they are Statements, Questions, Commands or Offers, along with their expected or discretionary responses (Halliday \& Mathiessen 2004, pp. 108-110). Along with their responses, these initiating utterances make up 'adjacency pairs.' Martin (1992, p. 40) assigns Speech Functions to clauses selecting independently for Mood, and this is the approach that is used in this paper.

Realizations of these Speech Functions in our data are categorized according to Mood (declarative, interrogative, or imperative). It is noted whether these realizations are congruent or not; for example, in discourse in general Commands are typically realized as imperatives, so it is noteworthy if they are expressed in other ways. When coding Questions I have noted whether they are 'direct' (congruently realized as interrogatives) or 'indirect' (reporting ideas, cf. Halliday \& Mathiessen 2004, p. 450). While coding for Mood I have also identified Tag Questions, where the Finite and Subject are repeated. The tag "serves to signal explicitly that a response is required, and what kind of response it is expected to be" (Halliday \& Mathiessen 2004, p. 109). Tag Questions are also believed to express a range of interpersonal meanings, such as uncertainty, 
inclusivity, facilitation, 'softening' and 'politeness' (e.g. Holmes 1992, p. 318ff), and they are noted here for this reason.

Following Birmingham School discourse analysis (e.g. Sinclair \& Coulthard 1975, Coulthard \& Montgomery 1981), Martin (1992, p. 46) refers to 'moves' in an exchange that is made up of more than simply an adjacency pair, as exemplified in our section above. Here we are using a combination of Exchange Structure and Speech Function in a similar way to Martin.

For an accessible description of the analyses above, please see Martin \& Rose 2007.

The main features of the discourse in the dataset are summarized below; for further discussion of these, please see Thwaite \& McKay 2013. Following this summary, I will focus on the features that distinguish the discourse of the trained teachers from that of the teacher aides. As an example of the contrast between teachers and teacher aides, I will look more closely at two lessons involving photography. One lesson was led by teacher Sara and the other by teacher aide (TA), Mrs Edgar, each of whom had a different group of children. (In keeping with the practice of the research team, I will refer to the teacher aide by her title). The discussion of the lessons will describe some of the features of the adults' discourse brought out by the analyses and point out some of the differences in their approaches.

\section{Results and discussion Register}

The apprenticeship of the children into scientific ways of talking is clear when the Field of discourse is examined. Scientific terminology, at the level of these children, is introduced. It is in the Tenor where the distinction between the teachers and teacher aides is clearest, as they establish different relationships with their young charges.

\section{Field}

The unit of work centred on an understanding of buildings and their purposes. Teachers designed hands-on learning experiences around this theme to engage the children in nine different activities over nine weeks. Activities included taking photos, investigating materials, measurement, construction, exploring scale and perspective, and using technologies. In the learning experiences the children were simultaneously learning how to learn, learning literacy and learning science concepts.

\section{Vocabulary}

Many of the learning experiences introduce the children to scientific terminology, with both teachers and teacher aides building up children's knowledge of the Field in this way. Most of the vocabulary used by the adults is for Labelling items, with much repetition from all the adults to reinforce vocabulary items (Thwaite \& McKay 2013). The teachers, as opposed to the TAs, sometimes also use Describing and Classifying (in terms of 'speech acts') with the more capable children. As these children are very young, the emphasis is on terminology rather than the more scientific processes of description and classification, although these do occur. The terms used by the teachers are more technical than those from teacher's aides. For example, Sara frequently uses words such as 'shape' and 'structure', which are linked to the focus concepts of the unit. 
In Example 1 (Table 1) below, she is focusing simultaneously on geometric terms, computer processes and spelling:

Table 1 Example 1*

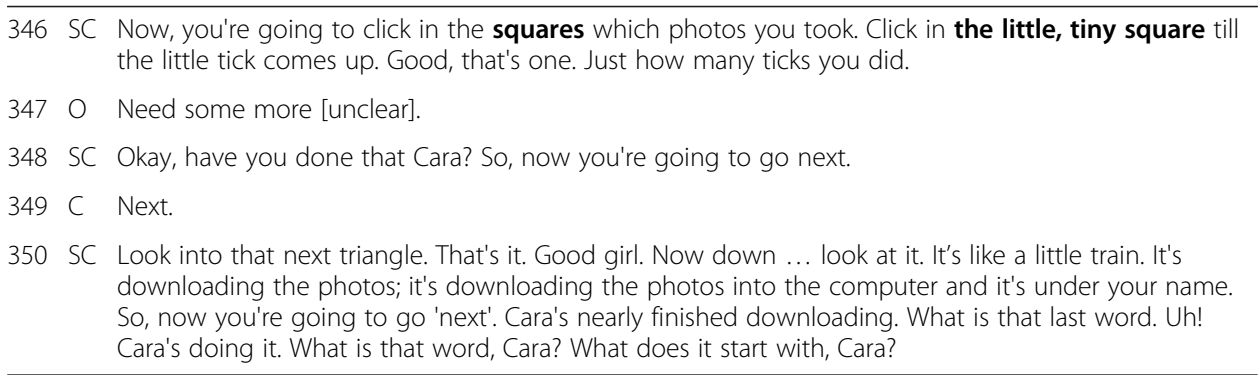

*Please note that in the transcripts $\mathrm{SC}=$ teacher Sara and $\mathrm{ME}=$ Mrs Edgar. Other initials refer to the names of children. All names given are pseudonyms.

The teachers, Sara especially, use some vocabulary that is relatively advanced for fiveyear-olds, more so than the TAs, as in Example 2 (Table 2) below:

\section{Table 2 Example 2}

83 SC Are you looking up on the roof? Just have a look first, we're not taking the photo yet. Now, what you need to do, you can take a photo of our new alfresco. You can take a photo of the pergola over here, have a look at what's holding the pergola up.

This contrasts with the same activity done by Mrs Edgar, without this type of vocabulary: see Example 3 (Table 3), below:

Table 3 Example 3

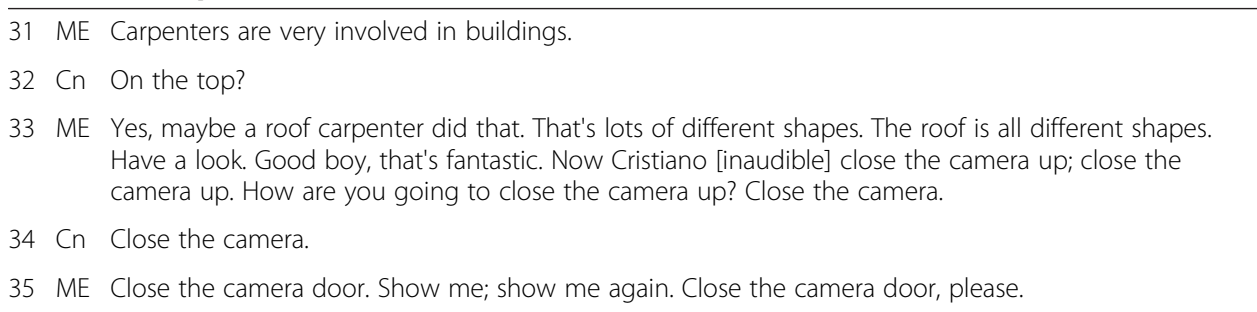

To help children organise their knowledge of the Field, the teachers provide generalizations and focus on processes like observation. These generalizations and observations could be seen as subgenres of the classroom discourse and may consist of more than one move. Thus, there are several differences between the teachers and teacher aides in terms of the technicality of the discourse and its approximation to talking scientifically, albeit at a five-year-old level.

\section{Tenor}

All the adults working with the children express positive relationships with them, and use praise. The teachers, especially Sara, relate to the children as if they are on the same level as adults in some ways, while of course ensuring that they can comprehend the discourse. Sara is more creative in her praise than the other teachers, for example when she says: "You're the lucky winner". Teachers also use humour to form positive relationships with the children. Sara, in particular, makes frequent use of this device, for example, remarking about a computer cable: "Is it a skipping rope?", and, about 
chewing gum: "You need to stop chewing that Amanda. I'm going to give you some sauce to put on it so you can swallow it."

Sara uses non-patronising phraseology, such as, "when you turn into an adult" rather than "when you grow up". The children are from many different kinds of backgrounds, and she responds positively to their different circumstances. The other adults do not display this type of inclusivity. Nearly all the adults use correct terms of address for the children; however, Mrs Edgar abbreviates the name of Yolanda, a Chinese girl, using only the first part of her name. The teachers were never heard to do this.

Of the teachers, Sara in particular displays knowledge of the children's backgrounds and circumstances. In contrast, Mrs Edgar treats dialect differences as if they are mistakes: see Example 4 (Table 4), below:

\begin{tabular}{lll} 
Table 4 Example 4 & \\
\hline 273 & ME & What did everybody do when they left their classroom? They all sat on the...? \\
274 & K & Mat. \\
275 & ME & And then what happened? \\
276 & K & We done our activities. \\
277 & ME & Pardon? \\
278 & K & We done our activities. \\
279 & ME & Pardon? \\
280 & K & We done our activities. \\
281 & ME & You did your activities, okay.
\end{tabular}

Here Mrs Edgar is trying to force Katrina, an Indigenous Australian girl, to use Standard Australian English (SAE). Katrina is clearly unaware that Mrs Edgar is focusing on a literacy aspect (dialect features) rather than the meaning of her utterance. Mrs Edgar is attempting to bring together two functions of her discourse: encouraging Katrina to recount what she has done, as well as teaching her a lesson about SAE. The result is a very confused child.

\section{The discourse}

Over the nine-week unit, the discourse as a whole is evenly distributed between adults and children, in terms of the total number of turns. In 4292 turns at talk, children produce 50.2\% and adults 49.8\% (Thwaite \& McKay 2013). This indicates the success of the teachers in creating an environment where children can actively participate. Among the adults, teachers dominate the discourse in terms of turn number and length. Of the total of 2136 turns of adult talk, teachers produce 77\% (Thwaite \& McKay 2013). The contribution from different children also varies greatly, with some children dominating. Children vary in their contribution according to the situation and which adult they are working with. For example, among the 'Bricklayers' group there are large differences between Cara, Jessica and Luc in the different contexts. Luc takes more turns (albeit very short ones) with Mrs Edgar (TA), who very deliberately sets out to get him to respond (Thwaite \& McKay 2013).

\section{Exchange structure}

In terms of the exchange, the typical structure of the discourse in our dataset is that the teacher initiates, usually with a Question, then allows various contributions from 
the children, sometimes with feedback along the way, before rounding off the interaction. All the adults studied seem conscious of turn allocation; however, the teachers carry this out in a different way to the teacher aides. Teacher Sara facilitates all children in a group having a turn, but also gives them opportunities to expand on and elaborate their turns, which often results in a rich discourse, for example the children's thoughtful discussion in Example 11, below. Mrs Edgar, the TA, concentrates more than the teachers on managing the children and getting them all involved, without necessarily developing their turns to a great extent; for an illustration of this, please see Example 6, below.

\section{Expanding on the discourse}

Teachers develop the discourse by adding information to children's utterances. Often this is just a single adjective. It may also be in the form of a Question, often an alternating Question. The type of elaboration, shown in Example 5, below, is typical of Sara:

\section{Example 5}

And did you make a building each? Did you make one big building together? [Children answer softly] You got to make one each. And are they all really interesting? And was it easy or hard? [Children answer softly] It was easy.

Sara expands on her meaning with exemplification. For example, she says, "Right, now you're going to take some photos of some structures. Could be the bike rack ...". She also uses a simile to describe the downloading icon on the computer: "It's like a little train." and a metaphor for the relationship between the camera and the computer: "Your camera's not glued into this." Mrs Edgar does not use any of these terms, traditionally considered to be rhetorical devices.

\section{'Teacher knows the answer' - dk1 moves}

Exchange Structure describes the type of 'display' Question where the teacher knows the answer as a 'Delayed primary knower' ( $\mathrm{dk} 1)$ move. These are illustrated in Example 6, below. While the teachers do make use of these moves, Mrs Edgar does them very frequently. For example, in Week 5 in 142 turns of talk she asks $28 \mathrm{dk} 1$ Questions, such as the ones in Example 6 (Table 5), below. The dk1 moves are sometimes used to check that the children have followed instructions, and sometimes simply to ensure that they are involved in the discourse. However, in line 6, Mrs Edgar genuinely does not know the answer to the Question. She uses the dk1s not only to get the children to predict what they will be doing, but especially for them to reflect on what they have

Table 5 Example 6

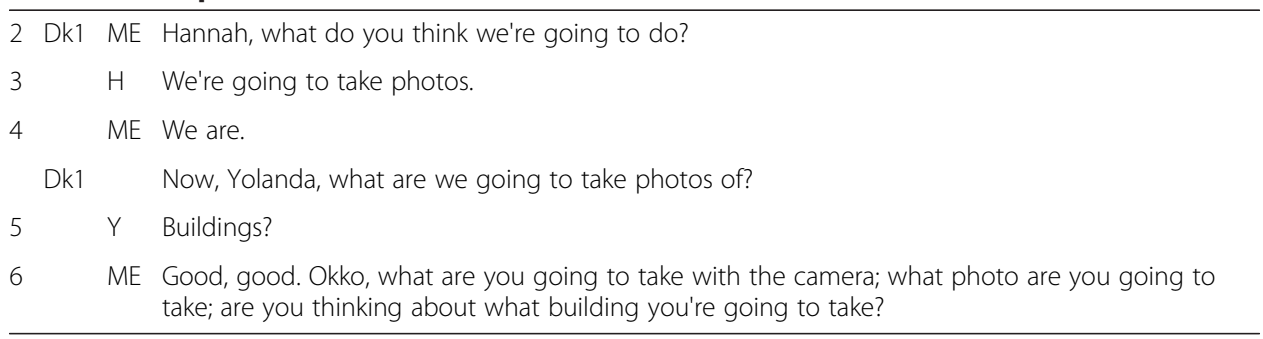


done. Both of these processes, prediction and reflection, are part of scientific method, as described, for example, in the Australian Science Curriculum:

"Science investigations are activities in which ideas, predictions or hypotheses are tested and conclusions are drawn in response to a question or problem." ACARA

Australian students in the third year of school are required to perform investigations and "Reflect on the investigation, including whether a test was fair or not." ACARA

Mrs Edgar sometimes answers her own dk1 Questions, for example: "What will we do, Bruce? Put them [photos] on the computer" and, "Do you think carpenters build cranes? No, they don't." In one example, Cristiano indicates that he knows the answer ("I know") but Mrs Edgar answers the Question herself. This is another feature that distinguishes the other adults from the teachers, who rarely answer their own Questions.

\section{Enabling children's answers}

Adults give prompts or hints to enable children to respond. For example, Sara says, "What shape are they? We just said it; we just said it right now."

Teacher Diane also gives prompts such as, "I think you told us before." Mrs Edgar also uses a hint, but of a different kind: "I wonder what you are? Hmm ... hmm? It starts with c-c-c..." Her hint differs from the teachers', in that they refer to previous discourse, modelling for the children a technique for answering questions in class. In contrast, Mrs Edgar is, as often, trying to elicit a particular word with a dk1 move, and refers to its pronunciation.

\section{Other strategies}

If a child does not give the expected response the adults rarely say that it is wrong. Instead they use various feedback strategies, or in some cases redirect or reframe the Question. Adults also ask different types of Questions so that children can build on their own contributions to produce extended turns.

\section{Speech function}

The discourse can be analysed according to Initiations (I), Responses (R) and Feedback (F) moves (Sinclair \& Coulthard 1975) and Speech Functions (Halliday 1994, p.69; Halliday \& Mathiessen 2004, pp. 108-110). The structure of the discourse can be described by the IRF pattern. This is typical of classroom discourse in general, where adults are overwhelmingly the ones doing Initiations, although occasionally children perform them. In saying that this is a typical pattern, I am not implying that teachers should follow this pattern, merely that it is a very common one.

The adults assign importance to acknowledging what children have said, although this is not always possible in groups of this size (approximately 50 when all the children meet together). As mentioned above, the adult nearly always initiates, usually with a Question, then different children respond. The adult sometimes gives feedback on 
these responses before concluding the discussion or introducing a new thread. These Questions and feedback are usually successful in encouraging contributions from the children. Adults almost never directly contradict the children; they will sometimes use Modality (Halliday \& Mathiessen 2004, pp. 146-150) to avoid doing this. In fact, teacher Sara tends to use Modality to soften her many of her utterances, as in Example 7 (Table 6) below where she is avoiding questioning Cristiano too intrusively:

\section{Table 6 Example 7}

\begin{tabular}{lll}
\hline 1 & SC & What sort of house are you making, Cristiano? \\
2 & Cn & My one has got something on there. \\
3 & SC & It's got something inside? \\
4 & Cn & Yeah. \\
5 & SC & What would that be? \\
\hline
\end{tabular}

\section{Commands}

Commands involve asking for Goods and Services (Halliday \& Mathiessen 2004, p. 107f). The adults in the dataset vary in the number of Commands they use, with the non-teachers using more, and more congruent ones. In the focus lessons, Mrs Edgar produces many Commands, often without attached reasons. In contrast, Sara, the teacher, models scientific discourse by giving reasons for phenomena. Mrs Edgar also produces more short Commands expressed as minor clauses, for example: "Two photos. Have a think about what carpenters take photos of. What work do they do? Two photos."

The teachers use incongruent Commands more than the other adults. Different types of Commands are part of Sara's wide range of strategies for involving the children in the lesson.

\section{Command complexes}

All the adults make use of Command complexes, groups of one or more Commands; however, the types of these differ. Sara's Command complexes are indicative of her particular style. Often she precedes her Commands with Questions, for example: 'What do you think the bike rack is made from? Have a look, go over.' and: 'See that little one there, press that one.' She also associates Commands with (explanatory) Statements or justifications, for example: 'We're going to look in there, but don't press it yet.' and 'Just have a look first, we're not taking the photo yet.' In another example, she explains how to hold the camera: 'Put your hand through there Missy Moo. That means you won't drop it.' Her tendency to give explanations also applies to larger units of text; for example, she tells the children how they are going to download the photos before they start doing it.

Sara also contextualizes her Commands by associating them with 'if' clauses, for example: 'If you need to go closer, come closer'. She precedes the Commands with anaphoric reference, possibly to focus children's attention, for example: 'Now, you're going to do this:...' and 'Press on this word, "clear all"'. As well, she follows her Commands with suggestions and examples. Her instructions become more specific if she realizes children have not understood, for example: 'You need to give him a bit of room. You need to move back my darling.' 
Thus, Sara uses many different types of Command complex, even solely within the focus lesson. This is not the case with Mrs Edgar. Her Command complexes involve more bare repetition rather than giving reasons, as in Example 8 (Table 7), below:

Table 7 Example 8

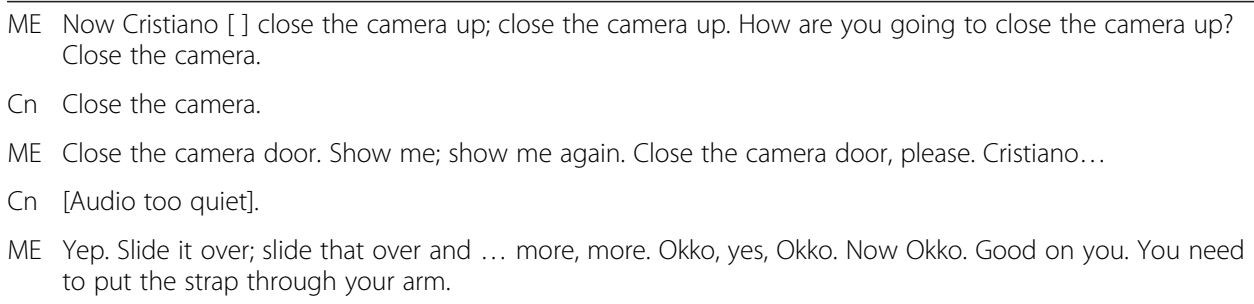

Another example from Mrs Edgar is shown in Example 9, below:

\section{Example 9}

"Hannah, you're next. Go and stand with Ollie and he'll give you the camera in one minute. Stop chewing. Hold it carefully. Slide the door across to close the camera, remember, each time. Pass it to Hannah. Have a think of ... try and remember the photos that you took with that ... Put the string through your ... Hannah that was great."

Overall her approach to the lesson focuses more on the process than the reasons for doing things. At one point she repeatedly asks, "What are we going to (do) now?" The children are carrying out actions without necessarily understanding why. Thus Mrs Edgar is not using this opportunity to model or develop the children's capacity for explanation.

\section{Questions}

Questions asked by the adults are sometimes WH- Questions, in some cases 'how' and 'why' Questions, but often closed Questions that predict a one-word answer. Even for the trained teachers in our data set, 71\% of Questions are closed (Thwaite \& McKay 2013). In the focus lessons, Mrs Edgar asks more closed Questions than Sara; many of these are dk1s (already discussed above). In comparison to the other adults, the teachers ask more Questions and their Questions are more varied. The teachers also ask more 'why' Questions than the other adults, such as, "What's holding this wall up? I wonder why there's sand in it, falling down." and, "What's holding that door on? I wonder why the door won't fall off the building." (both from Sara).

Mrs Edgar's Questions are sometimes not particularly interesting, for example: "What else do carpenters build?" Sara's Question: "What else can you see when you look up?" is somewhat similar, but differs because it is directing the children in the scientific process of observation (DuVall 2001), whereas Mrs Edgar's Question is asking them to think or possibly simply recall. In general, Mrs Edgar asks more procedural Questions, to which she already knows the answer, for example: "What are we going to (do) now?".

\section{Tag questions}

Sara uses many tag Questions. Sometimes they function as checks, perhaps to avoid contradicting the children, as shown in Example 10 (Table 8), below [tag Questions bolded]: 
Table 8 Example 10

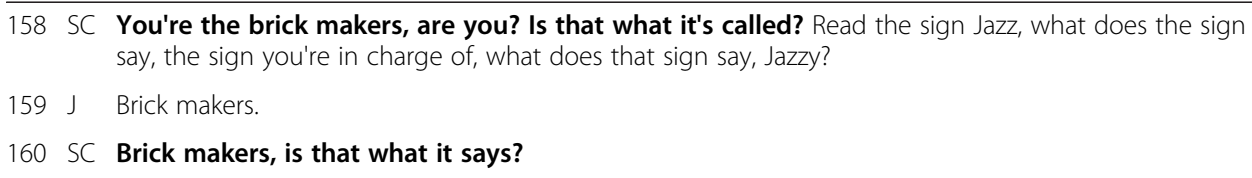

Sometimes Sara seems to use the tag Questions for inclusivity, for example in: "Oh, memory full. That didn't take many, did it? That's very strange.", where she treats the children as being equally knowledgeable about digital cameras as she is.

\section{Indirect questions}

Sara asks more indirect Questions than Mrs Edgar, for example, "I wonder what's holding the roof up?" Interestingly, this type of Question is also copied by at least one of the children; please see Example 11 (Table 9), below, for an illustration:

\section{Table 9 Example 11}

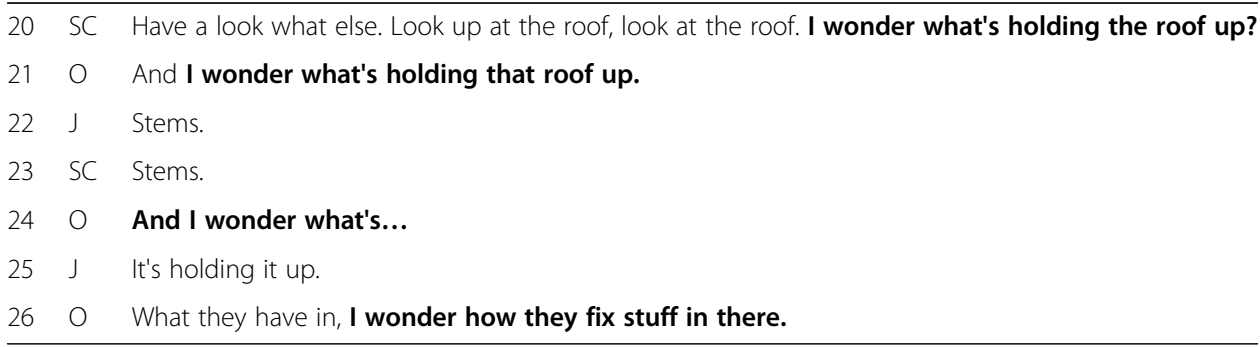

\section{Question complexes}

The adults use Question complexes in different ways. In the focus lessons, Mrs Edgar's Question complexes are more repetitive than Sara's, in the same way that her Command complexes are repetitive. This is illustrated below in Example 12:

\section{Example 12}

"What's the title of your group; are you bricklayers; are you painters; what's the title of your group? You are...?"

\section{Questions from the children}

It is also noticeable that the children ask less interesting Questions with Mrs Edgar than they do with Sara. For example, with Sara Questions include: "Are we allowed to take pictures of people and buildings in the background, with buildings in the background?" (thinking beyond the original task), "How is it glued onto the floor when there is no cement...?", "Why does it...?" and "What's the photo button?" With Mrs Edgar the Questions are mainly procedural, such as, "Excuse me, are we supposed to take our badges off?" Sara gives the children more autonomy in her responses to their Questions, for example: "No, well you told the answer yourself."

Overall, we find that across the Speech Functions of Command and Questions there is a clear difference between the teacher, Sara, and the teacher aide, Mrs Edgar, with 
Sara taking more opportunities to extend the discourse and encourage the children to think scientifically.

\section{Conclusions}

\section{Differences in the discourse}

This study has pointed to a number of differences between the trained teachers and other adults working with the children; in particular, the analysis of the focus lessons, where the children are learning about photography, has demonstrated differences between the approaches of the teacher, Sara, and the teacher aide, Mrs Edgar.

1. All the adults working with these children shape and control the discourse. However, the overall structure of the learning experiences focused on here, the photography sessions, is more interesting when led by the teacher. The teacher aide has a more formulaic approach to completing the activity, with interactions with different children taking a similar form.

2. In comparison to the other adults, teachers dominate the discourse in terms of turn number and length. This is to be expected as part of their role, and is also due to the fact that it was the teachers who conducted the whole class sessions (approximately 50 children).

3. All the adults control turn-taking, and in the focus lessons both the teacher and teacher aide are conscious of giving turns to a range of children. However, the teacher aide, Mrs Edgar, gives preference to equitable turn allocation as opposed to developing particular children's turns. This perhaps prevents some opportunities to go more deeply into scientific discourse. For the discourse as a whole, the number of turns is very evenly distributed between adults and children, with each group contributing approximately half the turns.

4. In the focus lessons on photography, the teacher expands on her meaning by giving many examples, and also uses the rhetorical devices of simile and metaphor. These strategies are not evident in the teacher aide's discourse.

5. All the teachers make use of "teacher knows the answer" (dk1) moves; however, teacher aide Mrs Edgar uses them very frequently. For example, in the focus lesson the moves make up nearly $20 \%$ of her turns. All of the adults in the data set mostly use closed Questions, but in the focus lessons this tendency is stronger for the teacher aide, who asks more Questions which are procedural and require short answers. In this context, teacher Sara asks more 'why' Questions encouraging thinking. Sara has a greater variety of Question types, with less repetition.

6. Teachers rarely answer their own questions, while the other adults do. Mrs Edgar is observed to do this even when a child indicates that he knows the answer.

7. Prompts and hints given by the teachers tend to be at a different level of language to those from the teacher aide Mrs Edgar. The teachers are more likely to refer to the preceding discourse, while Mrs Edgar refers to the phonology. Thus the teachers are giving more priority to meaning. The reference to the preceding text is part of the way in which the teachers produce a richer and more cohesive discourse than the other adults. 
8. The other adults use more Commands, including more congruent Commands (expressed as imperatives) than the teachers. Teacher Sara explains the sequence of events to the children before she tells them what to do.

9. In the focus lessons, Mrs Edgar produces more short Commands than teacher Sara, and does not usually give reasons for her Commands, focussing more on the processes involved in the lesson. In contrast, Sara models this aspect of scientific discourse.

10. In the focus lessons, both the teacher and the teacher aide use Command complexes (groups of Commands together). However, Sara uses a wider variety, involving explanation and reasoning, whereas Mrs Edgar's complexes involve more repetition.

11. In the focus lessons, children ask more interesting Questions with teacher Sara than with Mrs Edgar, demonstrating their progress towards thinking scientifically.

12. All the teachers use some advanced science and technology vocabulary, which the teacher aides do not use.

13. While most scientific vocabulary in the dataset is used for labelling, teachers also use the functions of describing and sometimes classifying.

14. The relationship constructed with the children by teacher Sara is different to that between the other adults and the children. An example of this is that Sara includes personal anecdotes and uses humour in her discourse.

15. The discourse of the teachers, particularly that of Sara, is more inclusive. The teacher aide Mrs Edgar did not appear to value vernacular dialects as a vehicle for learning and did not recognize a child's efforts to make meaning in her home dialect. This is significant given that these children were five years old and unlikely to be aware of dialect differences.

So the two types of adults, teachers and teacher aides, have different techniques but are both helping the children merge the two discourses of literacy and science. Both are dedicated professionals who give the children a great deal of praise and encouragement. No criticism of anything they have done is intended by this analysis. From this study, it does seem that the trained teachers produced a richer, higher level and more inclusive discourse than the teacher aides, in this particular context. This type of discourse would be more likely to assist the children towards an approximation of talking scientifically. Perhaps it would be possible to give the teacher aides professional development in such discourse or, preferably, engage them in collaborative reflection on classroom talk.

It is reassuring to know that there does appear to be a difference between the discourse of a three- or four-year trained teacher and a teacher aide! However, in order to generalize this finding we would need to undertake further research.

Abbreviations

Dk1: Delayed primary knower move (Berry, 1981a,b,c); IRF: Initiation/Response/ Feedback (Sinclair \& Coulthard, 1975);

PISA: Programme for International Student Assessment; SAE: Standard Australian English; TA: Teacher aide. 


\section{Acknowledgements}

Edith Cowan University Faculty of Education and Arts grant

Project director, Assoc. Prof. Caroline Barratt-Pugh.

Co-researcher, Assoc. Prof. Graham McKay.

Research assistant, Mrs Sandra Parsons.

Writing assistance, Dr John Hall.

An earlier version of this paper was presented to the European Systemic Functional Linguistic Congress \& Workshop,

July 2013, University of Bologna.

Received: 27 July 2013 Accepted: 18 September 2013

Published: 10 April 2014

\section{References}

ACARA (Australian Curriculum, Assessment and Reporting Authority). 2013a. Australian Curriculum Science. Accessed 11 September 2013. http://www.australiancurriculum.edu.au/science/Content-structure.

ACARA (Australian Curriculum, Assessment and Reporting Authority). 2013b. Australian Curriculum Science. Accessed 11 September 2013. http://www.australiancurriculum.edu.au/science/Curriculum/F-10.

Berry, M. 1981a. Systemic linguistics and discourse analysis: A multi-layered approach to Exchange Structure. In Studies in Discourse Analysis, ed. M. Coulthard and M. Montgomery, 120-145. London: Routledge \& Kegan Paul.

Berry, M. 1981b. Polarity, ellipticity, elicitation and propositional development, their relevance to the well-formedness of an exchange. Nottingham Linguistic Circular 10(1):36-63.

Berry, M. 1981c. Towards layers of Exchange Structure for directive exchanges. Network 2:23-32.

Coulthard, M, and M. Montgomery (eds.). 1981. Studies in Discourse Analysis. London: Routledge \& Kegan Paul.

DuVall, Rick. 2001. Inquiry in science: From curiosity to understanding. Primary Voices K-6 10(1):3-9.

Halliday, MAK. 1994. An Introduction to Functional Grammar, 2nd ed. London: Edward Arnold.

Halliday, MAK, and R. Hasan. 1985. Language, Context and Text: Aspects of Language in a Social-semiotic perspective. Geelong: Deakin University Press.

Halliday, MAK, and CMM Mathiessen. 2004. An Introduction to Functional Grammar, 3rd ed. London: Arnold.

Holmes, J. 1992. An Introduction to Sociolinguistics. London: Longman.

Jones, P, L Kervin, and S Mclntosh. 2011. The interactive whiteboard: Tool and/or agent of semiotic mediation. Australian Journal of Language and Literacy 34(1):38-60.

Martin, JR. 1992. English Text: System and Structure. Amsterdam: Benjamins.

Martin, JR, and D Rose. 2007. Working with Discourse: Meaning Beyond the Clause. London: Continuum.

New South Wales Department of Education and Training. 1999-2011. Investigating Scientifically K-12. http://www. curriculumsupport.education.nsw.gov.au/. Accessed 29 July 2013.

Rennie, LJ. 2005. Science awareness and scientific literacy. Teaching Science 51(1): 10-14.

Seefeldt, C, and A Galper. 2007. "Sciencing" and young children. Scholastic Early Childhood Today 21(7):12-13.

Sinclair, J, and M Coulthard. 1975. Towards an Analysis of Discourse: The English Used by Teachers and Pupils. Oxford: Oxford University Press.

Thwaite, A. 1993. Gender Differences in Spoken Interaction in Same Sex Dyadic Conversations in Australian English. Australian Review of Applied Linguistics, Series S 10:147-179.

Thwaite, A, and G McKay. 2013. Five-year-olds doing science and technology: How teachers shape the conversation. Australian Journal of Language and Literacy 36(1):28-37.

Ventola, E. 1987. The Structure of Social Interaction: A Systemic Approach to the Semiotics of Service Encounters. London: Pinter.

doi:10.1186/2196-419X-1-6

Cite this article as: Thwaite: Teachers and teacher aides initiating five-year-olds into science. Functional Linguistics 2014 1:6.

\section{Submit your manuscript to a SpringerOpen ${ }^{\circ}$ journal and benefit from:}

- Convenient online submission

- Rigorous peer review

- Immediate publication on acceptance

- Open access: articles freely available online

- High visibility within the field

- Retaining the copyright to your article

Submit your next manuscript at $\boldsymbol{\nabla}$ springeropen.com 